\title{
BMJ
}

\section{Effect of tailored practice and patient care plans on secondary prevention of heart disease in general practice: cluster randomised controlled trial}

\author{
A W Murphy, professor of general practice, ${ }^{1}$ M E Cupples, reader in general practice, ${ }^{2}$ S M Smith, senior \\ lecturer in primary care, ${ }^{3} \mathrm{M}$ Byrne, lecturer in primary care, ${ }^{4} \mathrm{M}$ C Byrne, lecturer in psychology, ${ }^{1} \mathrm{~J}$ Newell, senior \\ lecturer in biostatistics, ${ }^{5}$ for the SPHERE study team
}

\section{Department of General Practice, \\ National University of Ireland \\ Galway, Ireland \\ ${ }^{2}$ UKCRC Centre of Excellence for Public Health (Northern Ireland), \\ Queen's University Belfast, \\ Northern Ireland \\ ${ }^{3}$ Department of Public Health and Primary Care, Trinity College \\ Dublin, Ireland \\ ${ }^{4}$ School of Psychology, National University of Ireland Galway, Ireland \\ ${ }^{5}$ Health Research Board Clinical Research Facility, National University of Ireland Galway, Ireland}

Correspondence to: A W Murphy andrew.murphy@nuigalway.ie

Cite this as: $B M J$ 2009;339:b4220 doi:10.1136/bmj.b4220

\section{ABSTRACT}

Objective To test the effectiveness of a complex intervention designed, within a theoretical framework, to improve outcomes for patients with coronary heart disease.

Design Cluster randomised controlled multicentre trial.

Setting General practices in Northern Ireland and the Republic of Ireland, regions with different healthcare systems.

Participants 903 patients with established coronary heart disease registered with one of 48 practices.

Intervention Tailored care plans for practices (practice based training in prescribing and behaviour change, administrative support, quarterly newsletter), and tailored care plans for patients (motivational interviewing, goal identification, and target setting for lifestyle change) with reviews every four months at the practices. Control practices provided usual care.

Main outcome measures The proportion of patients at 18 month follow-up above target levels for blood pressure and total cholesterol concentration, and those admitted to hospital, and changes in physical and mental health status (SF-12).

Results At baseline the numbers (proportions) of patients above the recommended limits were: systolic blood pressure greater than $140 \mathrm{~mm} \mathrm{Hg}$ (305/899; 33.9\%, 95\% confidence interval $30.8 \%$ to $33.9 \%$ ), diastolic blood pressure greater than $90 \mathrm{~mm} \mathrm{Hg}(111 / 901 ; 12.3 \%, 10.2 \%$ to $14.5 \%)$, and total cholesterol concentration greater than $5 \mathrm{mmol} / \mathrm{l}(188 / 860 ; 20.8 \%, 19.1 \%$ to $24.6 \%)$. At the 18 month follow-up there were no significant differences between intervention and control groups in the numbers (proportions) of patients above the recommended limits: systolic blood pressure, intervention 98/360 (27.2\%) $\mathrm{v}$ control, 133/405 (32.8\%), odds ratio 1.51 (95\% confidence interval 0.99 to $2.30 ; \mathrm{P}=0.06$ ); diastolic blood pressure, intervention 32/360 (8.9\%) v control, 40/405 (9.9\%), 1.40 (0.75 to 2.64; $\mathrm{P}=0.29$ ); and total cholesterol concentration, intervention 52/342 (15.2\%) v control, 64/391 (16.4\%), 1.13 ( 0.63 to 2.03; $\mathrm{P}=0.65$ ). The number of patients admitted to hospital over the 18 month study period significantly decreased in the intervention group compared with the control group: $107 / 415(25.8 \%) \mathrm{V}$ 148/435 (34.0\%), 1.56 (1.53 to 2.60; $\mathrm{P}=0.03$ ). Conclusions Admissions to hospital were significantly reduced after an intensive 18 month intervention to improve outcomes for patients with coronary heart disease, but no other clinical benefits were shown, possibly because of a ceiling effect related to improved management of the disease.

Trial registration Current Controlled Trials ISRCTN24081411.

\section{INTRODUCTION}

Despite the substantial potential to reduce the risk of recurrent disease and death among patients with established coronary heart disease, initial reports on the implementation of prevention guidelines were disappointing. ${ }^{1}$ Systematic reviews of structured management programmes among these patients have, however, confirmed that such programmes improve both processes of care and clinical outcomes. ${ }^{2}$

Clarification of the optimal mix of components and provision of enhanced details of complex health service interventions are important. ${ }^{34}$ Many trials have been characterised by important limitations such as short follow-up, limited generalisability to primary care, and poor descriptions of interventions. ${ }^{3}$ A need for a phased and careful approach to the development of complex interventions and an emphasis on explicit theoretical foundations has been highlighted. ${ }^{4} \mathrm{McAlis}-$ ter and Moher ${ }^{35}$ showed that disease management programmes may not achieve expected returns when baseline management levels are high. In the presence of current fast changing environments, regarding both population changes and disease management programmes, it is even more important that the potential contributions of disease management programmes continue to be evaluated in controlled trials. Without such controls the impact of specific interventions could be overestimated. This is particularly pertinent today as whole health systems move to comprehensive disease management programmes, such as the quality and outcomes framework in the United Kingdom. ${ }^{6}$ 
We carried out a cluster randomised controlled trial of an intervention developed for patients with established coronary heart disease and designed to improve clinical outcomes in general practice. The intervention was developed according to the Medical Research Council framework, ${ }^{7}$ based on explicit theoretical frameworks, and the trial was done within the context of an increasing awareness of the importance of reducing cardiovascular risk in these patients.

\section{METHODS}

The trial methods have been reported previously. ${ }^{8} \mathrm{We}$ recruited general practices from two different healthcare systems in Ireland (box 1). The Republic of Ireland has a mixed healthcare system and Northern Ireland is served by the UK National Health Service.

An individual independent of the research team randomly selected practices in each of three geographical areas (based around three management centres: Belfast in Northern Ireland, and Dublin and Galway in the Republic of Ireland) using computer generated random numbers (www.random.org). The practices were telephoned to confirm their eligibility and to determine their interest in participating. Practices were eligible if they had a practice nurse involved in general patient care, had not participated in the pilot, had a prespecified minimum list size, and were not participating in Heartwatch (a programme of secondary prevention of cardiac disease involving $20 \%$ of practices in the Republic of Ireland). ${ }^{9}$ If a practice declined to participate, another was selected and invited in the same way until 16 in each centre had been recruited.

Participating practices prepared lists of all their patients with established coronary heart disease: documented myocardial infarction, coronary artery bypass grafting, angioplasty, or angina (confirmed by exercise stress test, isotope test, or coronary angiogram). We excluded those with major mental or physical illness

Box 1 Key features of healthcare systems in Northern Ireland and Republic of Ireland

\section{Northern Ireland}

Publicly funded (NHS)

No charges for access to primary care or hospital care

People are registered for primary care in a specified general practice; the practices are computerised and receive financial incentives for using disease registers and monitoring quality of care

Prescriptions are free to those who meet certain criteria, such as low income; others are asked to pay a nominal fee

\section{Republic of Ireland}

Mixed public and private funding

Primary health care is free through the General Medical Services scheme only to those judged less able to pay or, during the duration of this study, to those aged over 70 (32\% of population registered in 2005)

Registration with a practice is required only if the patient belongs to the General Medical Services scheme; practices have limited use of computers, few disease registers, and no specific financial incentives for operating a recall system to monitor patients' care

Free prescriptions are available only within the General Medical Services scheme; others pay the full costs of medicines up to a monthly limit (€90 (£84; \$134) per family in 2005)
Table 1| Characteristics of practices and patients at baseline. Values are numbers (percentages) unless stated otherwise

\begin{tabular}{|c|c|c|}
\hline Characteristics & Intervention & Control \\
\hline \multicolumn{3}{|l|}{ Practice factors } \\
\hline No of practices & 24 & 24 \\
\hline \multicolumn{3}{|l|}{ Practice size: } \\
\hline$<2$ whole time equivalents & $9(47)$ & $10(53)$ \\
\hline$\geq 2$ whole time equivalents & $15(52)$ & $14(48)$ \\
\hline \multicolumn{3}{|l|}{ Region: } \\
\hline Northern Ireland & $8(33)$ & $8(33)$ \\
\hline Republic of Ireland & $16(67)$ & $16(67)$ \\
\hline \multicolumn{3}{|l|}{ Patient factors } \\
\hline No of patients & 444 & 459 \\
\hline Mean (SD) age (years) & $68.5(9.3)$ & $66.5(9.9)$ \\
\hline Men & $311(70)$ & $320(70)$ \\
\hline $\begin{array}{l}\text { Mean (SD) years since diagnosis of } \\
\text { coronary heart disease }\end{array}$ & $8.3(6.6)$ & $8.2(6.5)$ \\
\hline Myocardial infarction & $220(50)$ & $233(51)$ \\
\hline Angina & $390(88)$ & $414(90)$ \\
\hline Diabetes & $78(17.6)$ & $82(17.9)$ \\
\hline Coronary artery bypass grafting & $114(25.7)$ & $124(27.1)$ \\
\hline $\begin{array}{l}\text { Percutaneous transluminal } \\
\text { coronary angioplasty }\end{array}$ & $126(28.4)$ & $149(32.6)$ \\
\hline $\begin{array}{l}\text { Eligible for General Medical } \\
\text { Services scheme* }\end{array}$ & $234(82.4)$ & $218(73.4)$ \\
\hline Married & $288(67)$ & $315(70)$ \\
\hline Manual occupation & $134(42)$ & $172(51)$ \\
\hline Completed secondary education & $179(42)$ & $145(33)$ \\
\hline
\end{tabular}

that was likely to impair their capacity to change lifestyle behaviour or assimilate new information. Potential participants from each practice were randomly selected (www.random.org) at a remote site and sent an invitation to participate, a reply slip, and questionnaires relating to physical and mental health status (SF12) and lifestyle (validated questionnaires for diet and exercise). We allowed six weeks for non-response, during which time reminders were posted. Patients were invited in sequence from lists in random order, until 20 in each practice had agreed to participate.

Those who consented attended a baseline consultation at their own practice, where the practice nurse measured their blood pressure (automated validated sphygmomanometer, Omron M7, Kyoto, Japan), waist to hip ratio, and body mass index; took a venous blood sample for serum cholesterol assay (non-fasting); and recorded prescribed drugs. Cholesterol assays were done in one of 15 local hospital laboratories, all of which participated in an external quality assurance scheme: either the UK National External Quality Assurance Service (www.ukneqas.org.uk), Welsh Quality Assurance Service (www.weqas.com), or both.

To minimise potential recruitment bias we collected baseline data before randomisation of practices to intervention and control groups. We chose a cluster randomisation design because our intervention aimed to alter practitioners' behaviour and this could contaminate their interactions with control patients. 
Box 2 Implementation of complex intervention (a more detailed description is available at http://trialsjournal.com/content/6/1/11)

\section{Tailored practice care}

An action plan for each practice was agreed with the practice and regularly reviewed by the study research nurse and practice

The study nurse maintained regular contact with the practices

The practice received a two page study newsletter every four months

\section{Academic detailing}

An academic general practitioner (one per centre) made one 90 minute educational outreach visit to each intervention practice to promote drug prescribing guidelines for secondary prevention through interactive case based scenarios

A study research nurse (one per centre) delivered another 90 minute session on behaviour change, which was intended to facilitate reflection on change to patient lifestyle and, through role play, new techniques to be used by the practice

\section{Tailored patient care}

At the first intervention consultation, the patient and practitioner together identified areas of management that could be improved and the patient was invited to prioritise one particular aspect of his or her lifestyle for change

Possible ways of achieving targets reflecting optimal management were identified and action plans individualised so that small, realistic goals for change were agreed

A booklet ${ }^{11}$ containing information on all the key risk factors for coronary heart disease was used by practitioners in discussions on initial target setting and then given to the patients

\section{Regular consultations}

Patients were invited for an appointment with the general practitioner or nurse every four months; targets and goals for optimal secondary prevention were reviewed at each visit

Practices were stratified according to numbers of whole time equivalent general practitioners in each practice $(<2$ and $\geq 2)$ and randomised using a process of minimisation within each centre by an individual independent of the research team. Baseline usual care for patients with established coronary heart disease was documented in all practices before randomisation and reviewed at follow-up. We checked the accuracy of data entry for a random 5\% sample of participants; accuracy was established for $97.1 \%$ of 1344 items reviewed.

We developed a multifaceted intervention comprising care plans for both the practices and the patients (box 2). ${ }^{10}$ By exploring practitioners' and patients' views, in accordance with the Medical Research Council framework, ${ }^{7}$ we determined the duration and intensity of training within the practices and the frequency of patient recall. As documented previously, ${ }^{12}$ social cognitive theory ${ }^{13}$ was the main psychological theory used to develop the training in behaviour change, design the booklet for intervention patients, ${ }^{11}$ and inform the development of tailored plans for patient care. According to this theory, building patients' self efficacy or self confidence and facilitating patients in setting goals and making action plans are central to the optimal management of chronic disease.

No contact was made with the control practices after the collection of baseline data. They continued with usual care, which in Northern Ireland involved a system for annual review of blood pressure, cholesterol concentration, smoking status, and prescribed drugs, in accordance with the criteria specified within the NHS general practitioner contract quality and outcomes framework for the management of coronary heart disease. Although practitioners sought to improve the management for patients who failed to meet targets related to those criteria, by adjusting drugs appropriately and giving advice on lifestyle, this was not within a structured format. In the Republic of Ireland usual care may have included monitoring of risk factors and providing appropriate advice and drug management when patients sought a repeat prescription, but this was not organised in a formal manner. Care for patients with coronary heart disease in both healthcare systems was usually opportunistic; none of the practices provided motivational interviewing on lifestyle changes or created individually tailored plans for patients with identified goals relating to targets for optimal secondary prevention. Further information on care within the two systems is reported elsewhere. ${ }^{14}$

After 18 months we sent questionnaires to the participating patients and invited them to attend their practices for a follow-up consultation with their practice nurse, who repeated measurements taken at baseline. Primary categorical outcomes were the proportions of patients not achieving target levels for blood pressure

Table 2 |Comparison of primary categorical outcomes at baseline and follow-up between intervention and control groups while adjusting for clustering, baseline differences, and prespecified covariates*. Values are percentages (numbers) unless stated otherwise

\begin{tabular}{|c|c|c|c|c|c|c|c|c|c|c|}
\hline \multirow[b]{2}{*}{ Variable } & \multicolumn{2}{|c|}{$\begin{array}{l}\text { Valid No at baseline/ } \\
\text { follow-up }\end{array}$} & \multicolumn{2}{|c|}{ Baseline } & \multicolumn{2}{|c|}{ Follow-up } & \multirow{2}{*}{$\begin{array}{l}\text { Intracluster } \\
\text { correlation } \\
\text { coefficient }\end{array}$} & \multirow[b]{2}{*}{$\begin{array}{l}\text { Odds ratio } \dagger \\
(95 \% \mathrm{Cl})\end{array}$} & \multirow[b]{2}{*}{$\begin{array}{c}P \\
\text { value }\end{array}$} & \multirow{2}{*}{$\begin{array}{l}\text { Adjust- } \\
\text { ment for } \\
\text { multiple } \\
\text { testing }\end{array}$} \\
\hline & $\begin{array}{l}\text { Intervention } \\
\text { group }\end{array}$ & $\begin{array}{l}\text { Control } \\
\text { group }\end{array}$ & $\begin{array}{l}\text { Intervention } \\
\text { group }\end{array}$ & $\begin{array}{l}\text { Control } \\
\text { group }\end{array}$ & $\begin{array}{l}\text { Intervention } \\
\text { group }\end{array}$ & $\begin{array}{l}\text { Control } \\
\text { group }\end{array}$ & & & & \\
\hline \multicolumn{11}{|l|}{ Blood pressure: } \\
\hline Systolic >140 mm Hg & $443 / 360$ & $456 / 405$ & $34.1(151)$ & $33.8(154)$ & $27.2(98)$ & $32.8(133)$ & 0.06 & 1.51 (0.99 to 2.30$)$ & 0.06 & 0.18 \\
\hline Diastolic $>90 \mathrm{~mm} \mathrm{Hg}$ & $443 / 360$ & $458 / 405$ & $13.3(59)$ & $11.4(52)$ & $8.9(32)$ & $9.9(40)$ & 0.29 & $1.40(0.75$ to 2.64$)$ & 0.29 & 0.58 \\
\hline Total cholesterol $>5.0 \mathrm{mmol} / \mathrm{l}$ & $424 / 342$ & $436 / 391$ & $21.7(92)$ & $22.0(96)$ & $15.2(52)$ & $16.4(64)$ & 0.65 & 1.13 (0.63 to 2.03$)$ & 0.65 & 0.65 \\
\hline Hospital admissions§ & $433 / 415$ & 449/435 & $24.5(106)$ & 31.8 (143) & $25.8(107)$ & $34.0(148)$ & 0.03 & $1.56(1.53$ to 2.60$)$ & 0.03 & 0.12 \\
\hline
\end{tabular}

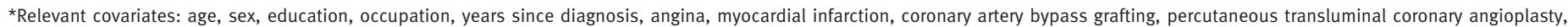
diabetes, region, practice size. Smoking status also considered for all measurements of blood pressure.

†Intervention group compared with control group.

$\ddagger$ See Holm 1979. ${ }^{21}$

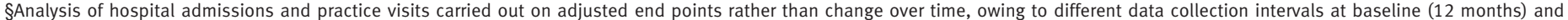
follow-up (18 months). 
and total cholesterol concentration, and who were admitted to hospital. An admission was attributed to a cardiac cause only if an explicit and acute cardiac diagnosis was stated as the primary or secondary reason for admission. Primary continuous variables were changes in physical and mental health status as measured by the SF-12. Indicators for diet were collected using the dietary instrument for nutrition education (DINE) questionnaire ${ }^{15}$ and exercise using the Godin questionnaire. ${ }^{16}$ The results of a parallel qualitative study involving interviews and focus groups with purposefully selected patients and practitioners will be reported separately.

\section{Sample size calculation}

Detailed sample size calculations are described elsewhere. ${ }^{8}$

Cholesterol-Based on an expected baseline proportion of $36 \%$ of patients with cholesterol levels greater

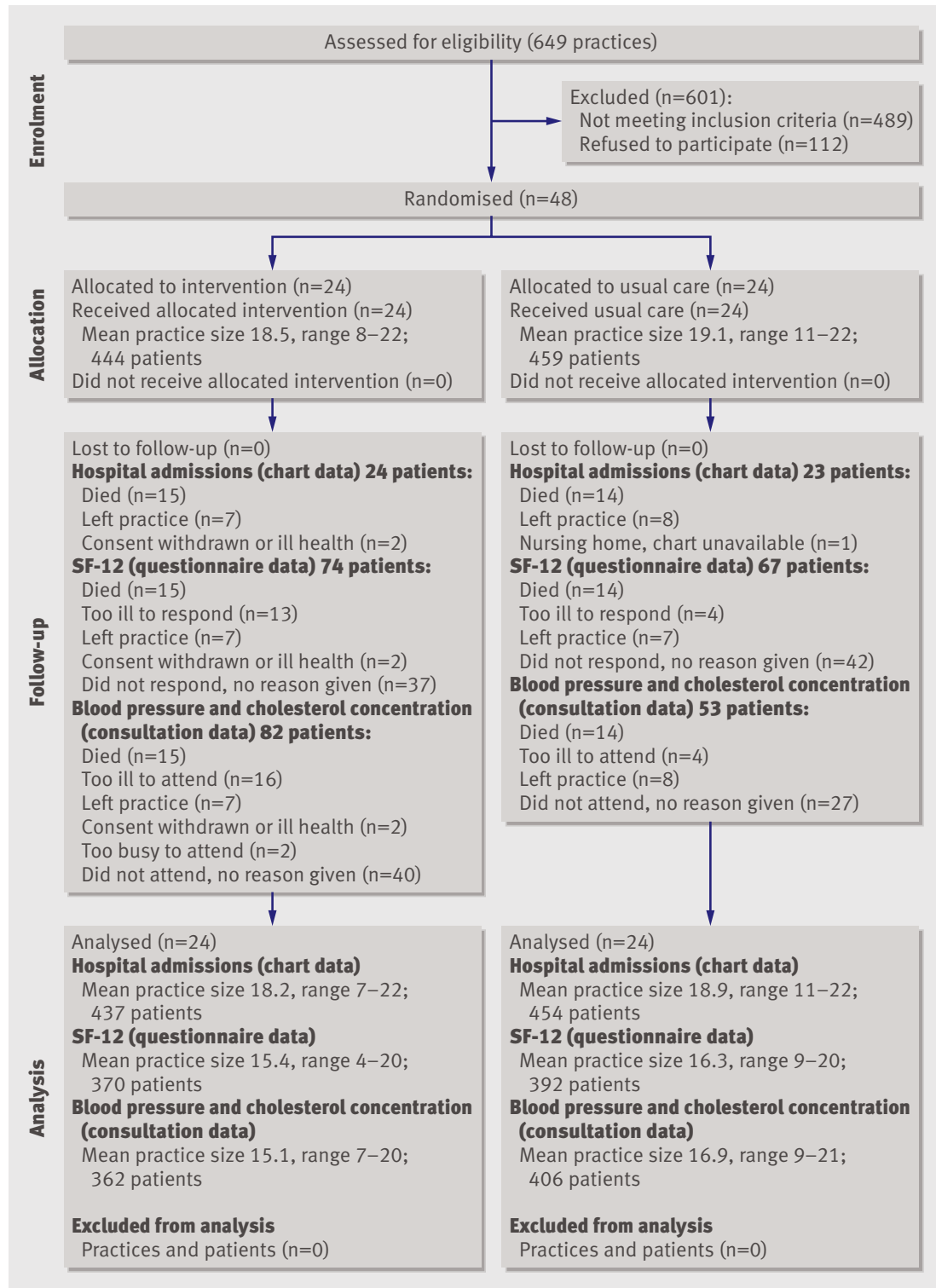

Fig 1| Flow of practices and patients through study than $5.0 \mathrm{mmol} / \mathrm{l}$ (J Leahy, personal communication, 2004) we estimated that a sample of 500 patients would allow detection, with $80 \%$ power and an $\alpha$ of 0.05, of an improvement (reduction) in the proportion of patients with cholesterol levels greater than $5.0 \mathrm{mmol} / \mathrm{l}$ by $50 \%$ in the intervention group and $20 \%$ in the control group. Allowing for a design effect size of 1.27 (estimated from a previously observed intracluster correlation coefficient of 0.019 (N Campbell, personal communication, 2001) and participation of 15 patients per practice) inflated the sample size requirement to 635 patients recruited from 42 practices. Allowing for practice attrition of $10 \%$ and $30 \%$ loss of patients to follow-up indicated that we needed to recruit 907 patients from 46 practices. To include equal numbers of practices within each of the three centres we recruited patients from 48 practices. This total sample size of 907 would allow the detection of clinically significant differences in the other primary outcomes with an $\alpha$ of 0.05 and power greater than $80 \%$.

Blood pressure -Based on previous reports, 44\% of patients were likely to have a baseline systolic blood pressure greater than $140 \mathrm{~mm} \mathrm{Hg}$ (J Leahy, personal communication, 2004), and an improvement of $20 \%$ in this proportion was likely in the control group. ${ }^{17}$ To detect a $50 \%$ improvement in the proportion of patients in the intervention group with a systolic blood pressure greater than $140 \mathrm{~mm} \mathrm{Hg}$ with $80 \%$ power and an $\alpha$ of 0.05 required a sample of 408 patients. Based on a design effect size of 1.15 (intracluster correlation coefficient $0.011^{17}$ and participation of 15 patients per practice) and allowing for $10 \%$ practice attrition and $30 \%$ patient attrition inflated this requirement to 670 patients from 34 practices.

SF-12-Based on a baseline mean of 53.98 (SD $8.39)^{18}$ for SF-12 physical and mental health status scores, we estimated that we would require a sample size of 120 patients to detect a clinically significant improvement of five points in these scores in the intervention group, with $80 \%$ power and an $\alpha$ of 0.05 . The intracluster correlation coefficient from previous data $^{18}(<0.001)$ indicated that there is no clustering effect for this variable and the design effect size is 0 . To allow for $10 \%$ practice attrition and 30\% patient attrition we estimated that a sample of 170 patients from 10 practices was required.

Hospital admissions - Previous data ${ }^{19}$ indicated that $43 \%$ of control patients had hospital admissions over two years. To detect a reduction in this by $50 \%$ in the intervention group and $20 \%$ in the control group with $80 \%$ power and an $\alpha$ of 0.05 we estimated that we required a sample size of 356 patients. Based on a design effect size of 1.08 (intracluster correlation coefficient 0.006 and participation of 15 patients per practice), indicated that the sample size should be inflated to 406 patients from 27 practices. We increased the sample size to 580 patients from 30 practices to allow for $10 \%$ practice attrition and $30 \%$ patient attrition. 
Table $3 \mid$ Comparison of continuous outcomes at baseline and follow-up in intervention and control groups while adjusting for clustering, baseline differences, and prespecified covariates*. Values are means (standard deviations) unless stated otherwise

\begin{tabular}{|c|c|c|c|c|c|c|c|c|c|}
\hline \multirow[b]{2}{*}{ Variable } & \multicolumn{2}{|c|}{$\begin{array}{c}\text { Valid No at baseline/ } \\
\text { follow-up }\end{array}$} & \multicolumn{2}{|c|}{ Baseline } & \multicolumn{2}{|c|}{ Follow-up } & \multirow{2}{*}{$\begin{array}{l}\text { Intracluster } \\
\text { correlation } \\
\text { coefficient }\end{array}$} & \multirow[b]{2}{*}{$\begin{array}{l}\text { Mean difference } \\
(95 \% \mathrm{Cl})\end{array}$} & \multirow[b]{2}{*}{$P$ value } \\
\hline & $\begin{array}{l}\text { Interven- } \\
\text { tion group }\end{array}$ & $\begin{array}{l}\text { Control } \\
\text { group }\end{array}$ & $\begin{array}{l}\text { Interven- } \\
\text { tion group }\end{array}$ & $\begin{array}{l}\text { Control } \\
\text { group }\end{array}$ & $\begin{array}{l}\text { Interven- } \\
\text { tion group }\end{array}$ & $\begin{array}{l}\text { Control } \\
\text { group }\end{array}$ & & & \\
\hline Systolic blood pressure (mm Hg) & $442 / 360$ & $451 / 405$ & $136.3(22.2)$ & $\begin{array}{l}136.8 \\
(21.2)\end{array}$ & $133.8(17.0)$ & $\begin{array}{l}137.9 \\
(19.3)\end{array}$ & 0.057 & $3.31(-1.02$ to 7.63$)$ & 0.13 \\
\hline Diastolic blood pressure $(\mathrm{mm} \mathrm{Hg})$ & $442 / 360$ & $451 / 405$ & $78.4(11.9)$ & $79.4(11.3)$ & $77.4(10.1)$ & $78.6(10.4)$ & 0.045 & $0.17(-2.16$ to 2.51$)$ & 0.88 \\
\hline Total cholesterol concentration (mmol/l) & $424 / 342$ & $436 / 391$ & $4.4(0.9)$ & $4.3(0.9)$ & $4.2(0.9)$ & $4.2(0.9)$ & 0.062 & $0.13(-0.03$ to 0.30$)$ & 0.11 \\
\hline No of hospital admissions per patient & $440 / 415$ & $452 / 435$ & $0.3(0.6) \dagger$ & $0.4(0.8) \dagger$ & $0.4(0.7) \ddagger$ & $0.5(1.0) \ddagger$ & 0.017 & $-0.15(-0.01$ to -0.29$)$ & 0.03 \\
\hline No of cardiovascular hospital admissions§ & 425 & 444 & NA & NA & $0.14(0.5)$ & $0.23(0.7)$ & 0.003 & $-0.11(-0.21$ to -0.01$)$ & 0.04 \\
\hline No of other hospital admissions per patient & 425 & 444 & NA & NA & $0.24(0.6)$ & $0.32(0.7)$ & 0.000 & $-0.06(-0.16$ to 0.04$)$ & 0.22 \\
\hline \multicolumn{10}{|l|}{ Primary continuous variables: } \\
\hline SF-12 physical component summary & $380 / 311$ & $382 / 338$ & $39.9(11.6)$ & $39.2(10.8)$ & $40.5(11.1)$ & $38.8(11.1)$ & 0.076 & $-0.78(-2.58$ to 1.03$)$ & 0.39 \\
\hline SF-12 mental component summary & $380 / 311$ & $382 / 338$ & $49.5(10.5)$ & $48.4(11.1)$ & $49.6(10.9)$ & $48.9(11.7)$ & 0.054 & $-0.02(-2.40$ to 2.35$)$ & 0.98 \\
\hline
\end{tabular}

$\mathrm{NA}=$ not applicable.

*See footnote to table 2 for relevant covariates.

†Over 12 months.

†Over 18 months.

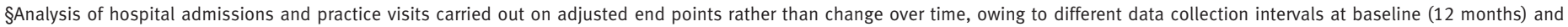
follow-up (18 months).

\section{Statistical analysis}

The statistical analyses are reported according to the CONSORT guidelines. ${ }^{20}$ To account for variability at baseline we calculated the response variables as the change from baseline measurements to follow-up. We analysed hospital admissions at follow-up while adjusting for baseline values: analysis of change was not appropriate owing to different intervals for data collection at baseline (12 months) and follow-up (18 months). This difference was caused by delays in recruitment, which resulted in a shift to one follow-up point at 18 months rather than the intended two at 12 and 24 months.

We used linear mixed effects regression models for all analyses to control for clustering (where each practice was incorporated as a random effect), randomisation stratifiers, and prespecified variables ${ }^{8}$ (age, sex, education, occupation, years since diagnosis, angina, myocardial infarction, coronary artery bypass grafting, percutaneous transluminal coronary angioplasty, diabetes, region, practice size). For all measurements of blood pressure we also considered smoking status. The estimated treatment group effect represents the difference in mean change from baseline in control patients compared with intervention patients.

When modelling the categorical response variables, we recoded each response as a binary variable to reflect whether the patient had improved or not-that is, remained unchanged or lacked improvement. For each binary response we used a generalised linear mixed model (using the binomial link function) while incorporating all confounding variables, using the same approaches as for the continuous responses. We present the results for the treatment effect for each binary response as the estimated odds of improvement for the response variable for those receiving the intervention relative to the controls. In addition to using linear mixed models, we used a clustered permutation test for each analysis as an alternative method to adjustments for any possible cluster effects.

Model checking was carried out using suitable model diagnostics and residual plots. All analyses were carried out using $\mathrm{R}$ (version 2.9.0) and Minitab 15 (Minitab, Coventry, UK), and adjusted for multiple testing. ${ }^{21}$

\section{RESULTS}

Figure 1 shows the flow of practices and patients through the study. In total, 489 practices were ineligible: $255(52 \%)$ had no practice nurse, $40(8 \%)$ had a small list size, $97(20 \%)$ were participating in Heartwatch (Republic of Ireland only), and 56 (12\%) had more than one criterion for exclusion. Data were missing for $41(8 \%)$ practices. Non-participating practices were asked why they had declined. The main reasons given were workload ( $\mathrm{n}=53)$, staff issues $(\mathrm{n}=19)$, not interested in this particular study or research in general $(\mathrm{n}=9)$, and miscellaneous (for example, involved in other initiatives, low remuneration) or not stated $(\mathrm{n}=31)$.

Overall, 1795 patients were invited to participate and 998 responded positively (55.6\%), with 903 subsequently attending a baseline consultation. All intervention practices took part in the educational visits and all practices completed the study. Forty two patients discontinued the intervention and 23 patients in the control group defaulted to follow-up, leaving 838 $(92.8 \%)$ patients who participated in follow-up. Data were collected between December 2004 and October 2007. Characteristics of the 48 participating practices and their existing populations were well balanced (table 1) apart from occupational status and educational level. These had been prespecified as covariates in the analysis.

At baseline the proportion of patients above the recommended limits for blood pressure $(140 / 90 \mathrm{~mm}$ 

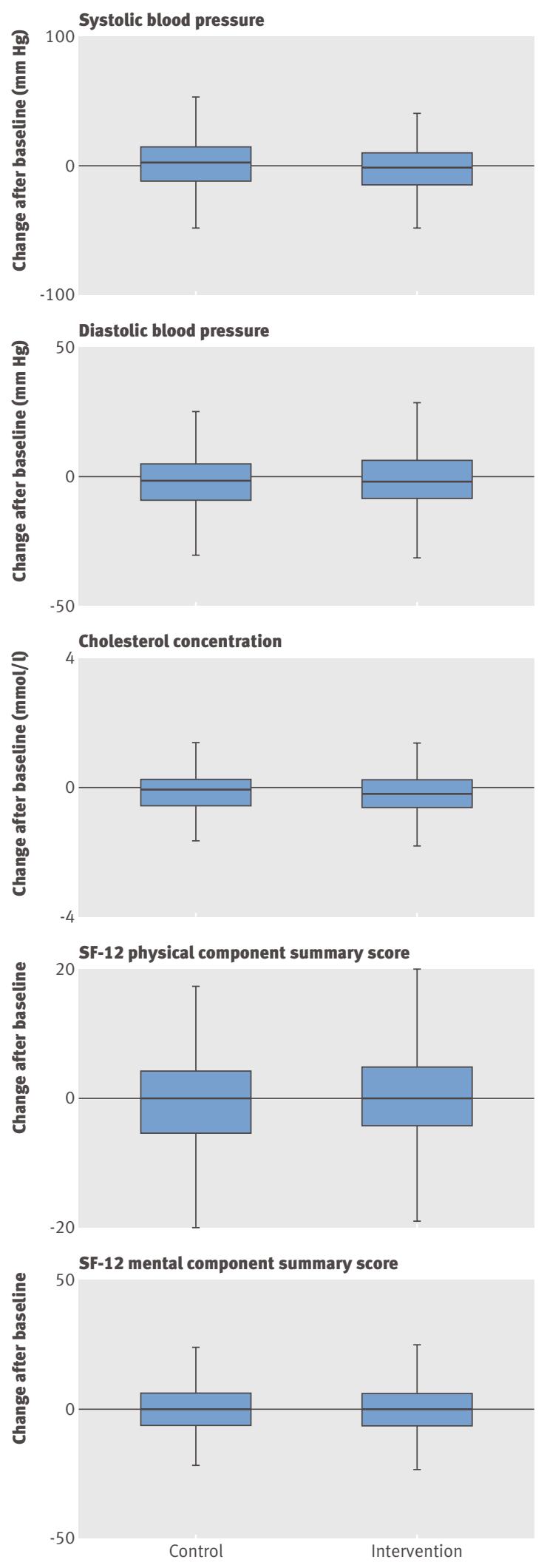

Fig 2 | Change in blood pressure, cholesterol concentration, and SF-12 physical and mental health components

$\mathrm{Hg})$ and total cholesterol concentration $(5 \mathrm{mmol} / \mathrm{l})$ were: systolic blood pressure 305/899 (33.9\%, 95\% confidence interval $30.8 \%$ to $33.9 \%$ ), diastolic blood pressure $111 / 901(12.3 \%, 10.2 \%$ to $14.5 \%)$, and cholesterol concentration $188 / 860(20.8 \%, 19.1 \%$ to $24.6 \%)$. Equivalent proportions at follow-up reflected a trend towards better control for all patients: systolic blood pressure $231 / 765(30.2 \%, 26.9 \%$ to $33.4 \%)$, diastolic blood pressure $72 / 765(9.4 \%, 7.3 \%$ to $11.5 \%)$, and cholesterol concentration $116 / 733 \quad(15.8 \%, 13.2 \%$ to $18.5 \%)$.

For any of the response variables of interest there was little evidence of any significant cluster effect regardless of whether the mixed models or clustered permutation test approach was used. As a consequence only the results of the mixed models approach are presented.

At baseline, similar proportions of patients in the control and intervention groups had blood pressure and cholesterol levels above recommended limits (table 2). Although the estimated treatment effects for blood pressure and cholesterol concentration reflected an improvement in the intervention group for both continuous and categorical responses, there were no significant differences between intervention and control groups at follow-up (tables 2 and 3). Figure 2 shows box plots of the changes in blood pressure, cholesterol concentration, and SF-12 physical and mental health components.

At baseline, different proportions of the control and intervention groups had been admitted to hospital in the previous 12 months (table 2); this was adjusted for in the analysis. A significant decrease was found in the intervention group for both the proportions of patients admitted (table 2) and the actual number of admissions per patient over 18 months (table 3). Further analysis showed that the numbers of admissions per patient for a cardiovascular event were significantly reduced for the intervention group, whereas there was no difference in numbers of hospital admissions for other causes (table 3).

The rates of visits to general practitioners did not change but rates of visits to the practice nurse in intervention practices significantly increased (table 4 ). The average length of consultations with an intervention practice nurse was 20.5 minutes (range 2-45 minutes).

Lifestyle changes are presented in table 5 . Intervention effects were non-significant. A trend for decreased smoking prevalence was observed in both intervention and control groups.

\section{DISCUSSION}

After 18 months a complex intervention aimed at improving the outcome for patients with coronary heart disease resulted in significant reductions in hospital admissions but no significant improvements in cholesterol concentration or management of blood pressure or change in mental or physical health status. Our baseline levels of blood pressure and cholesterol concentration were lower than in earlier studies, ${ }^{517192223}$ which themselves exhibited general progressive improvements since the late 1990s. The lower than anticipated numbers of patients exceeding target blood pressure and cholesterol levels may, 
although balanced by lower than expected practice and patient attrition rates and intracluster correlation coefficients, have introduced a potential type II error for these variables.

Adequate power was achieved for hospital admissions, where consistent and significant decreases were found for the intervention group in the proportions of patients admitted, the mean number of total admissions, and the mean number of hospital admissions for cardiovascular events per patient. The mean number of cardiovascular hospital admissions per patient was balanced by no significant differences in the number of admissions for other causes. Although the differences in admissions may be considered small, they do seem to be clinically significant. The intervention patients were 56\% $(95 \%$ confidence interval $1.53 \%$ to $2.60 \%$ ) less likely to be admitted than the control patients and for every 100 patients undergoing the intervention, 15 (95\% confidence interval 1 to 29) fewer admissions could be expected over an 18 month period (table 2). These results do, however, need to be interpreted cautiously as a difference in differences analysis was not possible owing to the change in time for collection of follow-up data. Adjustment for multiple testing also removed the finding of a significant reduction in number of hospital admissions. The need for such adjustment for independent outcomes remains controversial. ${ }^{24-26}$

Previous systematic reviews ${ }^{23}$ of management programmes for cardiac disease have highlighted their potential to decrease the number of hospital admissions, and noted that few actually report this outcome. We are the first to report a significant difference in cardiovascular admissions. A Cochrane review in this area $^{27}$ is ongoing, but the lack of detail on hospital admissions, which we report, is still lacking (B Buckley, personal communication, 2009).

How was this possible decrease in cardiovascular hospital admissions achieved in the absence of changes to either physiological or lifestyle variables (tables 2 and 3)? Previous studies have reported that self management programmes for chronic disease based on social cognitive theory increased levels of patient self efficacy and as a result reduced the utilisation of health services, including inpatient days ${ }^{2829}$ and outpatient visits. ${ }^{30}$ Although we did not measure levels of patient self efficacy, it is possible that as happened in these previous studies the intervention improved levels of self efficacy thereby increasing patients' confidence in their ability to manage their illness without access to health services. Although qualitative work may inform this discussion, these hypotheses require testing in future research.

In the Republic of Ireland a recent uncontrolled evaluation of a centrally funded initiative involving secondary cardiac prevention in $20 \%$ of practices nationally (the Heartwatch programme) found significant improvements in the management of blood pressure and cholesterol concentrations over almost three years. ${ }^{9}$ Our data from control practices, which were not participating in Heartwatch, suggest that improvements may be occurring through changes in the population ${ }^{31} 32$ and general system rather than through specific interventions in themselves. These changes may, for example, be occurring through increased societal and patient awareness of appropriate care, enhanced management of incident cases in hospital, or improved organisation of general practices in the management of chronic disease, particularly in prescribing. ${ }^{33}$ One study reported that improvements in the management of cardiovascular disease preceded the introduction of the new general practitioner contract in the UK, with its quality and outcomes framework, and the rate of improvement since then has remained similar. ${ }^{6}$

It may be that a ceiling effect has been reached in the secondary management of cardiovascular disease in primary care. Similar ceiling effects have been noted recently in relation to medical outcomes in patients with diabetes. ${ }^{34}$ The qualitative findings within our study (M D'Eath, personal communication, 2009) indicated that some patients found targeted changes unachievable or that their practitioners judged them to be unattainable. Consideration of this issue is important as significant resources are being given to support such interventions in the primary care management of cardiovascular disease and in the management of chronic disease generally. As resources are finite and workloads have increased, it may be that the focus of management programmes in the secondary prevention of cardiac disease in the community should be on those with additional absolute risk, such as patients with several morbidities ${ }^{3536}$ or those who are more disadvantaged. ${ }^{37}$

\section{Generalisability of the findings}

Researchers have recently systematically reviewed the internal and external validity of cluster randomised

Table 4 |Visiting rates in intervention and control group practices at baseline and follow-up while adjusting for clustering, baseline differences, and prespecified covariates*. Values are means (standard deviations) unless stated otherwise

\begin{tabular}{|c|c|c|c|c|c|c|c|c|c|}
\hline \multirow[b]{2}{*}{ Variable } & \multicolumn{2}{|c|}{$\begin{array}{l}\text { Valid No at baseline/ } \\
\text { follow-up }\end{array}$} & \multicolumn{2}{|c|}{ Baseline } & \multicolumn{2}{|c|}{ Follow-up } & \multirow{2}{*}{$\begin{array}{l}\text { Intracluster } \\
\text { correlation } \\
\text { coefficient }\end{array}$} & \multirow[b]{2}{*}{$\begin{array}{l}\text { Mean difference } \\
(95 \% \mathrm{Cl})\end{array}$} & \multirow[b]{2}{*}{$P$ value } \\
\hline & $\begin{array}{l}\text { Intervention } \\
\text { group }\end{array}$ & $\begin{array}{l}\text { Control } \\
\text { group }\end{array}$ & $\begin{array}{l}\text { Intervention } \\
\text { group }\end{array}$ & $\begin{array}{l}\text { Control } \\
\text { group }\end{array}$ & $\begin{array}{l}\text { Intervention } \\
\text { group }\end{array}$ & $\begin{array}{l}\text { Control } \\
\text { group }\end{array}$ & & & \\
\hline Visits to general practitionert & $397 / 426$ & $434 / 444$ & $5.5(3.8)$ & $4.8(4.2)$ & $8.3(5.7)$ & $7.6(6.0)$ & 0.105 & $0.29(-0.97$ to 1.56$)$ & 0.64 \\
\hline Visits to practice nurse $\dagger$ & $397 / 426$ & $434 / 444$ & $2.1(2.9)$ & $1.5(2.2)$ & $4.6(4.2)$ & $1.8(2.2)$ & 0.340 & 3.00 (1.75 to 4.15$)$ & 0.00 \\
\hline
\end{tabular}

*See footnote to table 2 for relevant covariates.

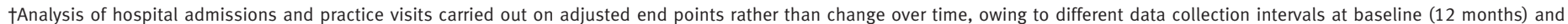
follow-up (18 months). 
Table 5 |Lifestyle secondary variables in intervention and control groups at baseline and follow-up while adjusting for clustering, baseline differences, and prespecified covariates*. Values are means (standard deviations) unless stated otherwise

\begin{tabular}{|c|c|c|c|c|c|c|c|c|}
\hline \multirow[b]{2}{*}{ Variable } & \multicolumn{2}{|c|}{$\begin{array}{l}\text { Valid No at baseline/ } \\
\text { follow-up }\end{array}$} & \multicolumn{2}{|c|}{ Baseline } & \multicolumn{2}{|c|}{ Follow-up } & \multirow{2}{*}{$\begin{array}{c}\text { Mean difference } \\
(95 \% \mathrm{Cl})\end{array}$} & \multirow[b]{2}{*}{$P$ value } \\
\hline & Intervention & Control & Intervention & Control & Intervention & Control & & \\
\hline Body mass index & $437 / 351$ & $451 / 399$ & $28.7(5.2)$ & $28.8(4.7)$ & $28.4(5.0)$ & $28.7(4.8)$ & $0.09(-0.32$ to 0.49$)$ & 0.67 \\
\hline Godin† exercise score & $256 / 249$ & $278 / 278$ & $22.6(20.7)$ & $18.9(17.2)$ & $23.9(23.7)$ & $21.1(21.7)$ & $-1.28(-7.25$ to 4.69$)$ & 0.67 \\
\hline \multicolumn{9}{|l|}{ DINE questionnaireł: } \\
\hline Fibre & $414 / 350$ & $436 / 366$ & $36.5(12.4)$ & $34.7(12.1)$ & $33.5(12.0)$ & $33.5(13.4)$ & $2.26(-0.07$ to 4.59$)$ & 0.06 \\
\hline Fat & $390 / 330$ & $415 / 343$ & $31.2(10.2)$ & $30.7(10.1)$ & $27.8(9.6)$ & $27.4(9.6)$ & $-0.19(-2.30$ to 1.92$)$ & 0.86 \\
\hline Unsaturated fat & $306 / 332$ & $323 / 341$ & $9.2(1.5)$ & $9.4(1.8)$ & $9.1(1.9)$ & $9.1(1.9)$ & $1.46(-0.41$ to 3.33$)$ & 0.12 \\
\hline Self reported smoker & $423 / 352$ & $438 / 378$ & $13.5(57) \S$ & $16.2(71) \S$ & $11.4(40) \S$ & $13.8(52) \S$ & 2.15 (0.65 to 8.39) & 0.23 \\
\hline
\end{tabular}

*See footnote to table 2 for relevant covariates.

†Scores range from zero upwards (no upper limit); score of $\geq 24$ represents active, $<24$ represents insufficiently active.

‡Scores for dietary instrument for nutrition education range from 1-132 (fibre), 7-122 (fat), and 3-12 (unsaturated fat); higher scores represent more fibre, fat, or unsaturated fat. $\S$ Percentage (number).

trials. ${ }^{38}$ We consider that the internal validity of the current trial is likely to be high as we accounted for clustering in both the sample size calculations and the analysis, and we protected against identification and recruitment bias for all eligible practice patients by timing randomisation after the collection of baseline data. One study ${ }^{39}$ highlighted such timing as the "cornerstone" of internal validity for individually randomised trials. Blind assessment of primary outcomes was not, however, possible, as is common in studies of this type.

The high number of ineligible practices largely reflects the low numbers of practice nurses in the Republic of Ireland at the time of practice recruitment. ${ }^{40}$ The practice nurse was a necessary and key component of the intervention, as exemplified by visiting rates (table 4). Since mid-2000 the availability of practice nurses in the Republic of Ireland has increased rapidly. With regard to external validity, one study ${ }^{38}$ emphasised the consideration of adoption (the extent to which the settings are representative of a wider population of settings) and implementation (the feasibility and acceptability of the intervention to health providers in clusters). Our 30\% recruitment rate for practices and $0 \%$ attrition rate are similar to the ranges reported previously. ${ }^{38}$ The feasibility of

\section{WHAT IS ALREADY KNOWN ON THIS TOPIC}

Structured programmes of care in primary care lead to improved provision of secondary prevention for patients with established heart disease, but expected returns may not be achieved when baseline management levels are high

\section{WHAT THIS STUDY ADDS}

Within the current context of secondary cardiac prevention provision in the United Kingdom and Ireland, further improvements in risk factor management are difficult to achieve

Current efforts in primary care should be maintained but future focus may be at the population level and on those patients with additional absolute risk or who are less likely to be receiving optimal therapy implementation was supported through quality assurance measures during observation of consultations, which were clearly not blinded. Parallel qualitative analysis seemed to confirm the acceptability of an intervention mediated through the practice nurse (M D'Eath, personal communication, 2009). The successful delivery of the trial simultaneously in two different health systems is noteworthy and should potentially increase generalisability. However, we cannot discount the possibility that selection bias might have favoured "good" practices and "compliant" patients, with the result that baseline performance was high with little scope for improvement.

\section{Limitations of the study}

The possibility of selection bias needs to be considered for both practices and patients. However, the baseline performance of participating practices in both Northern Ireland and the Republic of Ireland was similar to regional norms. Any possible impact of regional differences in provision of usual care has been accounted for by recruiting equal numbers of control and intervention practices in Northern Ireland and the Republic of Ireland. Patient selection bias should have been minimised both by practice allocation subsequent to baseline data collection and by the random selection of patients. The study may be underpowered for determination of blood pressure and cholesterol outcomes. Data collection was not blinded as is common in studies such as this one. Analysis of hospital admissions may have been affected by the different data collection periods at baseline and follow-up and consideration of adjustments for multiple testing.

Our findings suggest that, within the current context, attempts to improve further the provision of secondary cardiac care may result in lower numbers of cardiovascular hospital admissions but not other clinical benefits. Further exploration of the value of such interventions for those with additional risk or who are less likely to be receiving optimal therapy may be warranted.

The SPHERE study team also includes C Leathem, A Houlihan, M O'Malley, V Spillane, H Grealish, and P Ryan (research nurses); 
M Corrigan, M D'Eath, and J Wilson (qualitative researchers); and A Kelly, E O'Shea, P Gillespie, M Donnelly, J Hinde, A Alvarez, and A Simpkin (statistical, economic, and policy advisers). We thank the patients and practitioners in each of the participating practices: Medical Centre, Old Bawn Road, Tallaght; Medical Centre, Main Street, Kilcullen; Guinness Medical Centre, Dublin 8; Beechlawn Medical Centre, Monkstown; Medical Centre, Carrig, Kill, Co Kildare; Unit 3 Neilstown Shopping Centre, Clondalkin; Derrinturn Health Centre, Carbury, Co Kildare; Medical Centre, Main Street, Blessington, Co Wicklow; 276 River Forest, Leixlip; Ballymun Family Practice, Ballymun Health Centre, Dublin 11; Medical Centre, Main Street, Celbridge, Co Kildare; Kildare Medical Centre, Bride Street, Kildare, Co Kildare; Bray Family Practice, Meath Road, Bray, Co Wicklow; 2a Brookdale Walk, Swords, Co Dublin; 138 Collins Avenue, Whitehall, Dublin 9; 31 Hazelwood Court, Artane, Dublin 5; Springfield Medical Centre, Alderwood Avenue, Tallaght; Primary Care Centre, Mohill, Co Leitrim; Medical Centre, Carrigart, Co Donegal; Millbrae Surgery, Carndonagh, Co Donegal; Claddagh Medical Centre, The Crescent, Galway; Medical Centre, Westport Road, Clifden, Co Galway; 4 Howley Terrace, Ballina, Co Mayo; Grove Medical Centre, Westport, Co Mayo; Eastland House, Dublin Road, Tuam, Co Galway; Health Centre, Athenry, Co Galway; Medical Centre, Carrowmore, Knock, Co Mayo; Health Centre, Moville, Co Donegal; Caheroyn Crescent, Athenry, Co Galway; Medical Centre, Dublin Road, Tuam, Co Galway; 216 Upper Salthill, Galway, Co Galway; Medical Centre, Kevin Barry Street, Ballina, Co Mayo; Medical Centre, Bangor Erris, Co Mayo; Health Centre, Turloughmore, Co Galway; Bangor Health Centre, Newtownards Road, Bangor; Ballywalter Health Centre, Fowler Way, Ballywalter; Old Mill Surgery, Church Street, Newtownards; Duncairn Surgery, Duncairn Gardens, Belfast; Kerrsland Surgery,Upper Newtownards Road, Belfast; Glenavy Family Practice, Main Street, Glenavy, Crumlin; Skegoneill Health Centre, Skegoneill Avenue, Belfast; Level 2, Lisburn Health Centre; Comber Health Centre, Newtownards Road, Comber; 181 Falls Road, Belfast; The Health Centre, High Street Portaferry; Shankill Health Centres (1 and 2), Shankill Parade, Belfast; Loughview Medical Centre, Main Street, Kircubbin; Level 3, Lisburn Health Centre, Lisburn; Falls Road Medical Centre, Belfast; Stream Street Surgery, Downpatrick, Co Down; Woodbrook Medical Centre, Stewartstown Road, Dunmurry, Belfast

Contributors: AWM, MEC, and SMS conceived the study and together with $\mathrm{MB}$ and $\mathrm{MCB}$ participated in the design of the trial and intervention. All authors, together with JN, participated in the acquisition and analysis of data and in critical revision of the manuscript, and have seen and approved the final version. AWM is the guarantor.

Funding: This study was funded by the Health Research Board and Irish Heart Foundation. The funders had no part in the design of the study; the collection, analysis, and interpretation of the data; the writing of the report; and the decision to submit the article for publication.

Competing interests: None declared.

Ethical approval: This study was approved by the Irish College of General Practitioners and the Queen's University research ethics committee.

1 Kotseva K, Wood D, De Backer G, De Bacquer D, Pyörälä K, Keil U, et al. Clinical reality of coronary prevention guidelines: a comparison of EUROASPIRE I and II in nine countries. Lancet 2001;357:995-1001.

2 Clark AM, Hartling L, Vandermeer B, McAlister FA. Meta-analysis: secondary prevention programs for patients with coronary artery disease. Ann Intern Med 2005;143:659-72.

3 McAlister FA, Lawson FME, Teo KK, Armstrong PW. Randomised trials of secondary prevention programmes in coronary heart disease: systematic review. BMJ 2001;323:957-62.

4 Campbell NC, Murray E, Darbyshire J, Emery J, Farmer A, Griffiths F, et al. Designing and evaluating complex interventions to improve health care. BMJ 2007;334:455-9.

5 Moher M, Yudkin P, Wright L, Turner R, Fuller A, Schofield T, et al. Cluster randomised controlled trial to compare three methods of promoting secondary prevention of coronary heart disease in primary care. BMJ 2001:322:1338-42.

6 Campbell S, Reeves D, Kontopantelis E, Middleton E, Sibbald B, Roland M, et al. Quality of primary care in England with the introduction of pay for performance. N Engl/ Med 2007;357:181-90.

7 Campbell M, Fitzpatrick R, Haines A, Kinmonth AL, Sandercock P, Spiegelhalter D, et al. Framework for design and evaluation of complex interventions to improve health. BMJ 2000;321:694-6.

8 Murphy AW, Cupples ME, Smith S, Byrne M, Leathem C, Byrne MC. The SPHERE Study. Secondary prevention of heart disease in general practice: protocol of a randomised controlled trial of tailored practice and patient care plans with parallel qualitative, economic and policy analyses. [ISRCTN24081411]. Curr Control Trials Cardiovasc Med 2005;6:11

9 Heartwatch National Programme Centre, Independent National Data Centre. Heartwatch clinical report: March 2003 to December 2005second report. Dublin: Department of Health and Children, 2006.

10 Byrne M, Cupples ME, Smith SM, Leathem C, Corrigan M, Byrne MC, et al. Development of a complex intervention for secondary prevention of coronary heart disease in primary care using the UK Medical Research Council Framework. Am J Manage Care 2006;12:261-6

11 Leathem CS, Byrne MC, Cupples ME, Byrne M, Corrigan M, Murphy AW, et al. Using the opinions of coronary heart disease patients in designing a health education booklet for use in general practice consultations. Primary Health Care Res Develop J 2009;10:189-99.

12 Byrne M, Corrigan M, Cupples ME, Smith SM, Leathem C, Murphy AW The SPHERE Study: using psychological theory to inform the development of behaviour change training for primary care staff to increase secondary prevention of coronary heart disease. Ir J Psychol 2005;26:53-64.

13 Bandura A. Social foundation of thought and action. Engelwood Cliffs, NJ: Prentice-Hall, 1986.

14 Cupples ME, Byrne MC, Smith SM, Leathem C, Murphy AW. Secondary prevention of cardiovascular disease in different priman healthcare systems, with and without pay-for-performance. Heart 2008;94:1594-600.

15 Roe L, Strong C, Whiteside C, Neil A, Mant D. Dietary intervention in primary care: validity of the DINE method for diet assessment. Fam Pract 1994;11:375-81.

16 Godin G, Shephard RJ. A simple method to assess exercise behavior in the community. Can J Appl Sport Sci 1985;10:141-6.

17 Campbell NC, Ritchie LD, Thain J, Deans HG, Rawles JM, Squair JL. Secondary prevention in coronary heart disease: a randomised trial of nurse led clinics in primary care. Heart 1998;80:447-52.

18 Byrne M, Murphy AW. Secondary prevention of heart disease: a baseline survey of patients' lifestyles and service provision in the north western and western health boards. Research and Development Report No 2. Galway: Department of General Practice, National University of Ireland Galway, 2002.

19 Cupples ME, McKnight A. Randomised controlled trial of health promotion in general practice for patients at high cardiovascular risk. BMJ 1994;309:993-6.

20 Campbell MK, Elbourne DR, Altman DG. CONSORT statement: extension to cluster randomised trials. BMJ 2004;328:702-8.

21 Holm S. A simple sequentially rejective multiple test procedure. Scand J Stat 1979;6:65-70

22 Jolly K, Bradley F, Sharp S, Smith H, Thompson S, Kinmonth AL, et al. Randomised controlled trial of follow up care in general practice of patients with myocardial infarction and angina: final results of the Southampton heart integrated care project (SHIP). The SHIP Collaborative Group. BMJ 1999;318:706-11.

23 Khunti K, Stone M, Paul S, Baines J, Gisbourne L, Faroogi A, et al. Disease management programme for secondary prevention of coronary heart disease and heart failure in primary care: a cluster randomised controlled trial. Heart 2007;93:1398-405.

24 Bender R, Lange S. Adjusting for multiple testing-when and how? Clin Epidemiol 2001;54:343-9.

25 Feise RJ. Do multiple outcome measures require p-value adjustment? BMC Med Res Methodol 2002;2:8.

26 Rothman KJ. No adjustments are needed for multiple testing. Epidemiology 1990;1:43-6

27 Buckley B, Byrne MC, Dineen B, Smith SM. Service organisation for the secondary prevention of ischaemic heart disease. (Protocol) Cochrane Database Syst Rev 2007:4: CD006772. DOI: 10.1002/14651858.CD006772.

28 Wheeler JR, Janz NK, Dodge JA. Can a disease self management program reduce health care costs? The case of older women with heart disease. Med Care 2003;41:706-15.

29 Lorig KR, Sobel DS, Stewart AL, Brown BW, Bandura A, Ritter P, et al. Evidence suggesting that a chronic disease self management program can improve health status while reducing hospitalisation. A randomised controlled trial. Med Care 1999;37:5-14.

30 Lorig KR, Ritter P, Stewart AL, Sobel DS, Brown BW, Bandura A, et al. Chronic disease self management program: 2-year health status and health care utilisation outcomes. Med Care 2001;39:1217-23.

31 Hardoon SL, Whincup PH, Lennon LT, Wannamethee SG, Capewell S, Morris RW, et al. How much of the recent decline in the incidence of myocardial infarction in British men can be explained by changes in cardiovascular risk factors? Evidence from a prospective populationbased study. Circulation 2008;117:598-604 
32 Bennett K, Kabir Z, Unal B, Shelley E, Critchley JA, Perry I, et al. Explaining the recent decrease in coronary heart disease mortality rates in Ireland, 1985-2000. J. Epidemiol Community Health 2006;60:322-7.

33 DeWilde S, Carey IM, Richards N, Whincup PH, Cook DG. Trends in secondary prevention of ischaemic heart disease in the UK 1994 2005: use of individual and combination treatment. Heart 2008;94:83-8

34 Davies MJ, Heller S, Skinner TC, Campbell MJ, Carey ME, Cradock S, et al. Effectiveness of the diabetes education and self management for ongoing and newly diagnosed (DESMOND) programme for people with newly diagnosed type 2 diabetes: cluster randomised controlled trial. BMJ 2008;336:491-5.

35 Glynn LG, Reddan D, Newell J, Hinde J, Buckley B, Murphy AW. Chronic kidney disease and mortality and morbidity among patients with established cardiovascular disease: a West of Ireland community-based cohort study. Nephrol Dial Transplant 2007;22:2586-94

36 Smith SM, O'Dowd T. Chronic diseases: what happens when they come in multiples? Br J Gen Pract 2007;57:268-70.

37 Capewell S, O'Flaherty M. Maximising secondary prevention therapies in patients with coronary heart disease. Heart 2008;94:8-9.

38 Eldridge S, Ashby D, Bennett C, Wakelin M, Feder G. Internal and external validity of cluster randomised trials: systematic review of recent trials. $B M J$ 2008;336:876-80.

39 Schulz KF, Altman DG, Moher D. Allocation concealment in clinical trials. JAMA 2002;288:2406-7.

40 O'Dowd T, O'Kelly M, O'Kelly F. Structure of general practice in Ireland 1982-2005. Dublin: Irish College of General Practitioners, 2006.

Accepted: 30 June 2009 